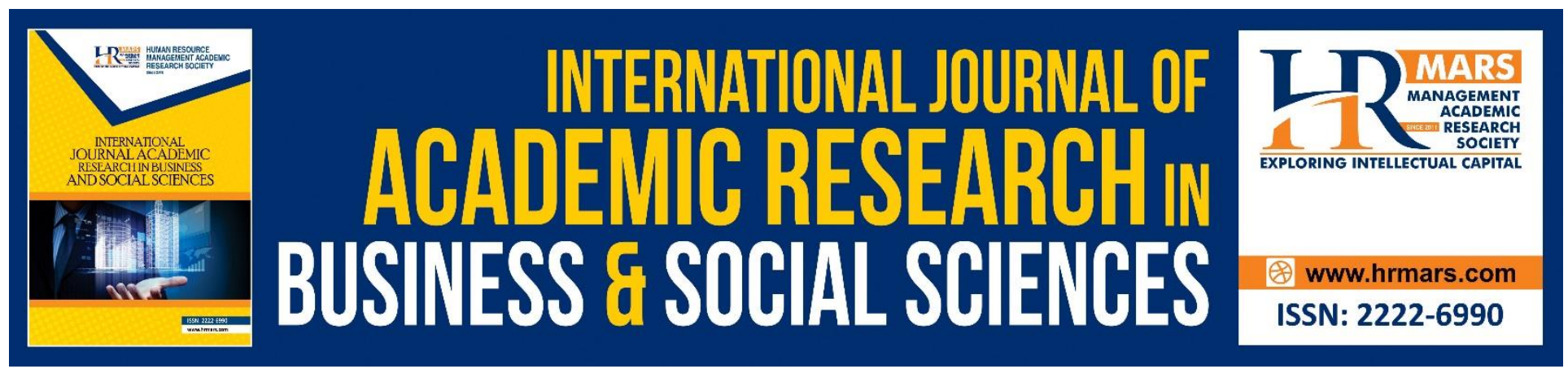

\title{
The Effect of Gain Versus Loss Framing of Covid-19 Online News on Preventive Behavior
}

\author{
Joanneia Selin Joseph, Julia Wirza Mohd Zawawi \& Akmar Hayati Ahmad \\ Ghazali
}

To Link this Article: http://dx.doi.org/10.6007/IJARBSS/v11-i15/10646

DOI:10.6007/IJARBSS/v11-i15/10646

Received: 16 May 2021, Revised: 19 June 2021, Accepted: 10 July 2021

Published Online: 27 July 2021

In-Text Citation: (Joseph et al., 2021)

To Cite this Article: Joseph, J. S., Zawawi, J. W. M., \& Ghazali, A. H. A. (2021). The Effect of Gain Versus Loss Framing of Covid-19 Online News on Preventive Behavior. International Journal of Academic Research in Business and Social Sciences, 11(15), 197-205.

\section{Copyright: (C) 2021 The Author(s)}

Published by Human Resource Management Academic Research Society (www.hrmars.com)

This article is published under the Creative Commons Attribution (CC BY 4.0) license. Anyone may reproduce, distribute, translate and create derivative works of this article (for both commercial and non-commercial purposes), subject to full attribution to the original publication and authors. The full terms of this license may be seen

at: http://creativecommons.org/licences/by/4.0/legalcode

Special Issue: Empowering Youth and Community Wellbeing for Sustainable Development, 2021, Pg. 197 - 205 http://hrmars.com/index.php/pages/detail/IJARBSS JOURNAL HOMEPAGE

Full Terms \& Conditions of access and use can be found at http://hrmars.com/index.php/pages/detail/publication-ethics 


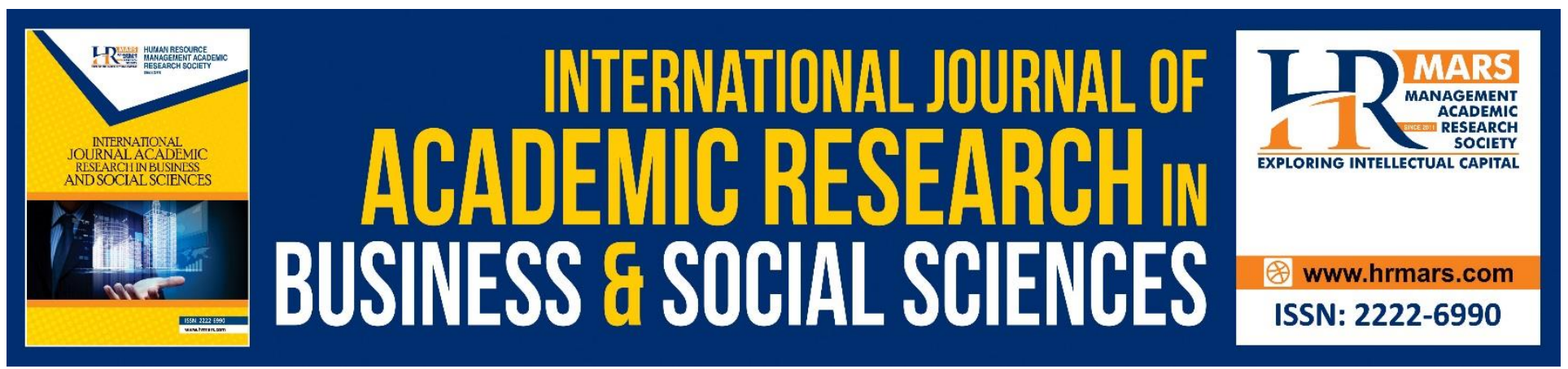

\title{
The Effect of Gain Versus Loss Framing of Covid-19 Online News on Preventive Behavior
}

\author{
Joanneia Selin Joseph ${ }^{1}$, Julia Wirza Mohd Zawawi ${ }^{1}$ \& Akmar Hayati \\ Ahmad Ghazali ${ }^{1,2}$ \\ ${ }^{1}$ Department of Communication, Faculty of Modern Languages and Communication, Universiti \\ Putra Malaysia, 43400 Serdang, Selangor Darul Ehsan, Malaysia, ${ }^{2}$ Institute for Social Science Studies, \\ Universiti Putra Malaysia, 43400 Serdang, Selangor Darul Ehsan, Malaysia \\ Email:wirza@upm.edu.my
}

\begin{abstract}
World Health Organization announced the coronavirus as a pandemic on March $11^{\text {th }} 2020$. The outbreak caused a massive destruction globally affecting more than 200 countries. During pandemic, information regarding the control of spreading, infectious cases, prevention, preparedness and risks are the important elements of public health. Media plays an important role here in delivering all this kind of information during the crisis. This is because media is the mediator of health communication between both the public and the government. Media framing influence public's preventive behaviour differently in terms of positive and negative framing. Their framing is capable enough to influence one's health behaviour and response to the disease differently. The purpose of this review paper is to examine how gain and loss framing influence COVID-19 preventive behaviours differently. This study chooses two main theories which are Valence Framing theory and Health Belief Model (HBM). This study draws the relationship between gain and loss as news framing effects, with perceived threat, perceived evaluation and self-efficacy as components of HBM. The combination of these two theories would be great tool for future studies to research on preventive behaviors. Besides that, this study will help the media to understand which frame (positive or negative) can educate the society and raise public health behaviours. This may also help the government to plan strategies for better health outcome practices from the public.
\end{abstract}

Keywords: COVID-19, Media Framing, Valence Framing, Health Belief Model, Gain Framing, Loss Framing

\section{Introduction}

The World Health Organisation (WHO) officially declared the COVID-19 outbreak as a "pandemic" on March $11^{\text {th }} 2020$ after a worldwide spread with millions of deaths. Severe acute respiratory syndrome (SARS)-CoV-2, or also known as Coronavirus Disease 2019 (COVID-19) has caused a rapidly spreading outbreak centered from China (Layne et al., 2020). The Malaysian government declared a nationwide lock down under the movement control order (MCO) starting $18^{\text {th }}$ March allowing only essential services to continue its operation after the rise in active cases. 
During crucial times like this, information regarding the control of spreading, infectious cases, prevention, preparedness and risks are the important element of public health and public tend to rely on non-medical sources such as news to gather information. When it comes to seeking information, the role of media cannot be underestimated (Pieri, 2019) because people's need for information increase especially during pandemics and global-health crisis (Iwai, 2020; Collinson et al., 2015). This is because media emphasizing different angle and providing various media frames may lead to different effects on public's attitudes and behaviors (Ophir, 2018).

Media framing studies are not something new in the context of pandemic or health communication and recently have been widely recognized by many during COVID-19 (Mutua and Ong'ong'a, 2020; Nwakpu et al., 2020; Ogbodo et al., 2020). In fact, one of the recognized framing effect research is the valence framing. Valence framing is the phenomenon of determining gains and losses in terms determining information in positive or negative (Zezelj et al., 2007). This is the most popular concept in health communication to study prevention and detection behavior (Hameleers, 2020) and has been widely used to examine human-related behavior (Gonzalez et al., 2005).

Hence, this research aims at examining the effect of both gain and loss frames of COVID-19 news. Adding on the note, the effects will be examined on preventive behaviors by the public. The most relatable model to explain this type of health communication is the Health Belief Model (HBM). HBM is well known for its wide usage in behavioural research specially to understand human health-related behaviours (Raamkumar et al., 2020; Jones et al., 2015). Thus, effects on preventive behaviours will be examined by combining valance frames with HBM components. Researcher will focus only on online news due to the speculation of facts that claimed approximately 3 billion regular social media users in database was recorded ever since the outbreak and was found keep increasing day by day (Iwai, 2020). SimilarWeb (2021) reported Malaysiakini online news portal ranking number one among the public. Considering the popularity of this online news, the research will pick two stories from Malaysiakini to be examined.

In order to understand the relationship between effects of gain and loss frames on COVID-19 preventive behaviors (Perceived Threat, Perceived Evaluation and Self-Efficacy), this research will focus towards the effect of gain frames on HBM components, the effect of loss frames on HBM components and the comparison between both frames. Overall, the objectives of the research are to study the relationship between gain and loss frames towards COVID-19 preventive behaviors (Perceived Threat, Perceived Evaluation and Self-Efficacy), effect of gain frames and loss frames on HBM component and comparing the differences between both frames.

\section{Valence Framing Theory}

Framing theory is the fundamental concept of this research. The concept of framing was first proposed by Gregory Bateson in 1954 defining the psychology frames as a "spatial and temporary bounding of set of interactive messages" which work in a multi-communication structure (Arowolo, 2017). The framing concept was then initiated by Erving Goffman, a classical sociologist in 1974 who assumed that the audience can never understand the "world as a whole" (Zawawi et al. 2014). Framing has been a "multidisciplinary" structure which contributes to research and studies on media effects on public (Ardèvol-Abreu, 2015). Scheufele (1999) elaborated that framing theory was believed to be the natural extension from the agenda setting theory. 
Valence framing originated from prospect theory by Kahneman and Tversky (1979). But valence framing only focuses on gain and loss without involving risk seeking or risk aversive. Valence framing is the phenomenon of determining gains and losses in terms determining information in positive or negative (Zezelj et al., 2007). Generally, framing effect can be examined by framing in terms benefits of practicing a specific behaviour (gains) and faults of not practicing a specific behaviour (losses) (Soofi et al., 2020). The theory is divided into three different types of framing effects: risky choice framing, attribute framing and goal framing.

Risky choice framing effects originated from the "Asian disease problem" by Tversky and Kahneman (1981) in which, individual choice to select risk or riskless decision depend on whether the decision are positively framed (save lives) or negatively framed (loss lives). Attribute framing directly examine the impact of positive and negative framing through a measure called evaluation. In this case, evaluation exist in the form of ranking likeliness (i.e. ranking an event on a scale of unsatisfactory to satisfactory, or tolerable to intolerable) or judging based on yes/no criteria (Will you continue in this event?) (Levin et al. 1998). Goal framing is well known in persuasive communication, where the framing effect depend on whether the message portray positive outcome of engaging the behavior or negative outcome of engaging the behavior. In fact, it is developed to strengthen the evaluation of behavior (Levin et al. 1998).

To be precise, this study will examine goal framing from the valence framing theory. This is due to the speculation in this theory which describes that goal framing was actually developed to strengthen the evaluation of behavior (Levin et al. 1998). Furthermore, the constant involvement of goal framing in health-related persuasive messages and the active use of promoting health-behavior studies (Levin et al. 1998) compared with the other two effects support the decision of adapting this particular framing into this study. The Figure 1 below illustrates goal framing structure.

Figure 1: Goal Framing Structure

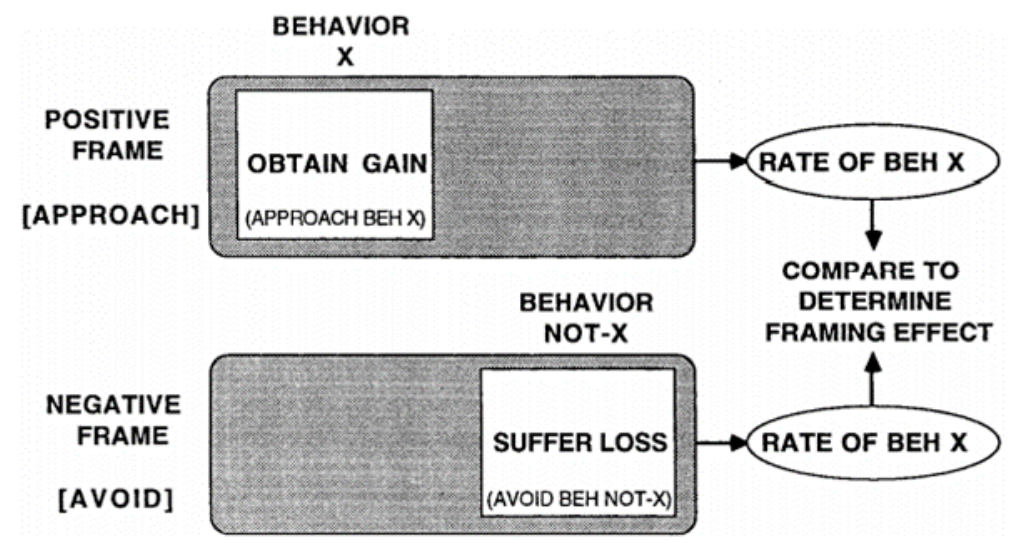

Note. Goal framing structure. Adapted from "All Frames Are Not Created Equal: A Typology and Critical Analysis of Framing Effects", by Lewin, Schneider and Gaeth, 1998, Organizational Behavior and Human Decision Processes, 76(2), p. 167. Copyright 1998 by Academic Press.

\section{Health Belief Model (HBM)}

Health Belief Model (HBM) was earlier initiated by social psychologists, Irwin M. Rosenstock, Godfrey M. Hochbaum, S. Stephen Kegels, and Howard Leventhal (Louis, 2017) at the U.S Public Health Service 
in the 1950s discussing about why people fail to involve in disease prevention programmes (Barakat and Kasemy, 2020). The model was actually developed to investigate the flop of a free tuberculosis (TB) health screening event. Later, the model was modified to analyse how people reply to disease symptoms and change their behaviours.

HBM can be classified into two types of models: Baseline model and Intermediate model. Baseline model is made up of four variables: Perceived Susceptibility, Perceived Severity, Perceived Benefit and Perceived Barrier. These four variables are classified into two main individual's view on healthy behaviors: Perceived Threat and Perceived Evaluation (Orji et al., 2012; Abraham and Sheeran, 2015). Perceived Threat consist of two variables which are Perceived Susceptibility and Perceived Severity. It happens when a person understands the risk they may face in a health condition. Perceived susceptibility is the likelihood a person set to private vulnerability in forming the health condition. Perceived Severity defines how serious a person trusts the result of practicing a health behavior will be (Orji et al. 2012). Meanwhile, Perceived Evaluation consists of two variables: Perceived Benefits and Perceived Barriers. It happens when a person trusts that engaging a particular behaviour will reduce harm from a disease. Perceived Benefits is the person's internal view towards the effectiveness of practicing a health behavior to balance the Perceived Threat. Perceived Barrier defines a person's internal judgement towards the obstacles in engaging the target behavior (Orji et al. 2012). Intermediate model is the extension of Baseline model by adding two variables: Cue to Action and Self-Efficacy. Cue to Action stimulate a particular health behavior when accurate trusts are held. Self-Efficacy explain a person's trust towards their capability to practice a behavior.

Among six HBM variables, only four variables will be measures as preventive behaviors. For Baseline model, literatures claim that Perceived Threat can be evaluated with perceived susceptibility alone because perceived severity is said to produce lesser variations with perceived susceptibility (Louis, 2017) and may even result in avoidance of protective behaviours due to its weaker correlation with health conditions (Orji et al., 2012). Due to its slight variance as indicated by literatures, this study will measure perceived threat with perceived susceptibility alone. Next, literatures claim that Perceived Evaluation can be examined by both variables in it because, perceived benefits act directly to new behaviour and they may get influenced by perceived barriers. Hence, perceived benefits cannot be neglected as perceived severity (Louis, 2017). For Intermediate model, Self-Efficacy was the strongest determinant of health behavior. Cue to action was found have weak or no effect on health behaviour (Barakat and Kasemy, 2020; Orji et al., 2012) and hold the weakest effect on protective behavior (Yuen et al. 2020). Thus, this research will focus Perceived Threat (Perceived Susceptibility), Perceived Evaluation (Perceived Barriers and Perceived Benefits) and Self-Efficacy only.

\section{Valence Framing and COVID-19}

In valence framing theory, goal framing has been widely used in health-related persuasive messages and promoting health-behavior studies (Levin et al. 1998). Recently, this framing has also been widely applied to study the COVID-19 pandemic and distinguished gain frames enhance better protective behaviour than loss frames. The statement was proven through several literatures. For instance, Biroli et al (2020) reported gain frames enhance more protection behaviour than loss frames in their study while conducting a COVID-19 survey in US, UK and Italy. 
Hameleers (2020) distinguished that gain frames contribute to prevention behaviours higher than loss frames which encouraged public to stay at home (self-isolation) to stop the COVID-19 outbreak. He strongly suggested that, in order to obtain effective preventive actions and positive outcomes such as social isolation, government must depend on gain frames instead of loss frames. Hence, if the media wishes public to follow strict preventions as proposed by other nations, first they should practice reporting gains (benefits of staying at home) than losses (loss of not following the measures). Soofi et al (2020) claimed that 94 meta-analysis studies proved gain frames increase more preventive behaviours and was a helpful intervention for framing health communication in COVID-19 prevention. Rao et al (2020) again commonly concluded that gain frame is acceptable for disease prevention while loss frame is acceptable for disease detection.

Furthermore, Dorison et al (2020) showed another great example of how WHO uses gain and loss frames in their website on April 16th 2020, an execution in which the outcome from this action can clarify with scientifically-acquired and trusted source. The website stated:

Gain frames: "Follow advice given by your healthcare provider, your national and local 3 public health authority or your employer on how to protect yourself and others from COVID-19".

Loss frames: "These measures can reduce working days lost due to illness and stop or slow the spread of COVID-19 if it arrives at one of your workplaces."

\section{Health Belief Model and COVID-19}

Meanwhile, HBM have been widely used recently in health behavioural studies especially in identifying preventive behaviours (Barakat and Kasemy, 2020; Jose et al. 2020; Raamkumar et al. 2020; Shahnazi et al. 2020; Yuen et al. 2020). HBM was frequently adapted in most of the behavioural studies involving COVID-19 pandemic. For instance, Raamkumar et al (2020) examined public perception during COVID-19 based on HBM. He measures the main four variables from the baseline model and concluded a significant mean rate for all four. Next, Barakat and Kasemy (2020) examined preventive behaviours among Egyptians during COVID-19 using HBM constructs. They both observed perceived susceptibility, benefits and barriers associate with preventive behaviours while cue to action has no effect.

Next, Jose et al (2020) examined public perception and preparedness during COVID-19 in Kerala, India using all HBM constructs. They found perceived susceptibility at $65.4 \%$, perceived severity at $44.3 \%$, perceived benefits at $63.1 \%$ indicating their likelihood to follow prevention measures during pandemic. Meanwhile, self-efficacy at $65.9 \%$ and perceived barriers at $65.9 \%$ indicating they were confident in avoiding infection and too much news contributes a little conflict as barriers. Shahnazi et al (2020) examined preventive behaviours during COVID-19 in Iran and distinguished that selfefficacy, benefits and barriers have the highest predictive power towards COVID-19 preventive behaviours.

\section{Future Perspectives of Framing Studies in Communication}

Examining news framing effects helps to widen the understanding of framing theory and this expansion help in advance of news gathering practices in various media platforms especially during pandemic in Malaysia. Since the COVID-19 outbreak in early January, research on gain and loss 
framing on this pandemic especially in Malaysia is still less. There is lesser proper empirical study to examine individual behavioural changes influenced by different news frames in any form of extant literature in Malaysia. Future scholars and researchers may have this study as a form of reference material in conducting similar studies on researching framing effect for pandemic in Malaysia. The study between both valence framing and HBM will be a great source of contribution for this new collaboration in research.

\section{Conclusion}

The current COVID-19 outbreak is still fresh and new to the current world. In this context, Valence framing in terms of gain and loss will be the IV, while Health Belief Model (HBM) in terms of Perceived Threat, Behavioral Evaluation and Self-Efficacy will be the DV. The expansion of communication technology today, allows public to demand for health information to select their own preferable information during a health crisis. By conducting this study, the media would be certain about how their level of framing influence public. Through this, the media would be able to restructure their way of framing for a better public understanding.

\section{References}

Abraham, C., \& Sheeran, P. (2015). The health belief model. In M. Conner \& P. Norman (Eds.), Predicting and changing health behaviour (3rd ed., pp. 30-69). Open University Press.

Ardèvol-Abreu, A. (2015). Framing theory in communication research: Origins, development and current situation in Spain. Latin Journal of Social Communication, 70, $423-450$. https://doi.org/10.4185/RLCS-2015-1053

Arowolo, S. O. (2017). Understanding framing theory. Research Gate. https://www.researchgate.net/publication/317841096_UNDERSTANDING_FRAMING_THEO RY

Barakat, A. M., \& Kasemy, Z. A. (2020). Preventive health behaviours during coronavirus disease 2019 pandemic based on health belief model among Egyptians. Middle East Current Psychiatry, 27(43). https:/doi.org/10.1186/s43045-020-00051-y

Biroli, P., Bosworth, S., Giusta, M. D., Girolamo, A. D., Jaworska, S., \& Vollen, J. (2020). Framing the predicted impacts of covid-19 prophylactic measures in terms of lives saved rather than deaths is more effective for older people (IZA Discussion Paper No. 13753). IZA Institute of Labor Economics. https://www.iza.org/publications/dp/13753/framing-the-predicted-impacts-ofcovid-19-prophylactic-measures-in-terms-of-lives-saved-rather-than-deaths-is-moreeffective-for-older-people

Collinson, S., Khan, K., \& Heffernan, J. M. (2015). The effects of media reports on disease spread and important public health measurements. PLOS ONE, 10(11). https://doi.org/10.1371/journal.pone.0141423

Dorison, C. A., Lerner, J. S., Heller, B. H., Rothman, A. J., Kawachi, I. I., Wang, K., Rees, V., Gill, B. P., Gibbs, N., \& Coles, N. (2020). A global test of message framing on behavioural intentions, policy support, information seeking, and experienced anxiety during the COVID-19 pandemic. PsyArXiv. https://doi.org/10.31234/osf.io/sevkf

Gonzalez, C., Dana, J., Koshino, H., \& Just, M. (2005). The framing effect and risky decisions: Examining cognitive functions with fMRI. Journal of Economic Psychology, 26(1), https://doi.org/10.1016/j.joep.2004.08.004 
INTERNATIONAL JOURNAL OF ACADEMIC RESEARCH IN BUSINESS AND SOCIAL SCIENCES

Vol. 11, No. 15, Empowering Youth and Community Wellbeing for Sustainable Development, 2021, E-ISSN: 2222-6990 @ 2020 HRMARS

Hameleers, M. (2020). Prospect theory in times of a pandemic: The effects of gain versus loss framing on policy preferences and emotional responses during the 2020 coronavirus outbreak Evidence from the US and the Netherlands. SocArXiv.

https://doi.org/10.1080/15205436.2020.1870144

Iwai, Y. (2020). Harnessing social media for the COVID-19 pandemic. Scientific American. https://blogs.scientificamerican.com/observations/harnessing-social-media-for-the-covid19-pandemic/

Jones, C. L., Jensen, J. D., Scherr, C. L., Brown, N. R., Christy, K., \& Weaver, J. (2015). The health belief model as an explanatory framework in communication research: Exploring parallel, serial, and moderated mediation. Health communication, 30(6), 566-576. https://doi.org/10.1080/10410236.2013.873363

Jose, R., Narendran, M., Bindu, A., Beevi, N., L. M., \& Benny, P. V. (2020). Public perception and preparedness for the pandemic COVID 19: A health belief model approach. Clinical Epidemiology and Global Health, 9, 41-46. https://doi.org/10.1016/j.cegh.2020.06.009

Kahneman, D., \& Tversky, A. (1979). Prospect theory: An analysis of decision under risk. Journal of the Econometric Society, 47(2), 263-291. https://www.uzh.ch/cmsssl/suz/dam/jcr:0000000064a0-5b1c-0000-00003b7ec704/10.05-kahneman-tversky-79.pdf

Layne, S. P., Hyman, J. M., Morens, D. M., \& Taubenberger, J. K. (2020). New coronavirus outbreak: Framing questions for pandemic prevention. Science Translational Medicine, 12(534). https://doi.org/10.1126/scitranslmed.abb1469

Levin, I. P., Schneider, S. L., \& Gaeth, G. J. (1998). All frames are not created equal: A typology and critical analysis of framing effects. Organizational Behavior and Human Decision Processes, 76(2), 149-188. https://doi.org/10.1006/obhd.1998.2804

Louis, J. P. I. (2017). Examining constructs of the health belief model as predictor of Haitian men's intention regarding prostate cancer screening [Doctoral dissertation, Barry University]. Sigma Repository. http://hdl.handle.net/10755/621199

Mutua, S. N., \& Ong'ong' a, D. O. (2020). Online news media framing of COVID-19 pandemic: Probing the initial phases of the disease outbreak in international media. European Journal of Interactive Multimedia and Education, 1(2). https://doi.org/10.30935/ejimed/8402

Nwakpu, E. S., Ezema, V. O., \& Ogbodo, J. N. (2020). Nigeria media framing of coronavirus pandemic and audience response. Health Promotion Perspectives, 10(3), 192-199. https://doi.org/10.34172/hpp.2020.32

Ogbodo, J. N., Onwe, E. C., Chukwu, J., Nwasum, C. J., Nwakpu, E. S., Nwankwo, S. U., Nwamini, S., Elem, S., \& Ogbaeja, N. I. (2020). Communicating health crisis: A content analysis of global media framing of COVID-19. Health Promotion Perspectives, 10(3), 257-269. https://doi.org/10.34172/hpp.2020.40

Ophir, Y. (2018). Spreading news: The coverage of epidemics by American newspapers and its effects on audiences - a crisis communication approach [Doctoral dissertation, University of Pennsylvania]. Publicly Accessible Penn Dissertations.

Orji, R., Vassileva, J., \& Mandryk, R. (2012). Towards an effective health interventions design: An extension of the health belief model. Online Journal of Public Health Informatics, 4(3). https://doi.org/10.5210/ojphi.v4i3.4321

Pieri, E. (2019). Media framing and the threat of global pandemics: The ebola crisis in UK media and policy response. Sociological Research Online, 24(1), $73-92$. https://doi.org/10.1177/1360780418811966 
Raamkumar, A. S., Tan, S. G., \& Wee, H. L. (2020). Use of health belief model-based deep learning classifiers for COVID-19 social media content to examine public perceptions of physical distancing: Model development and case study. JMIR Public Health and Surveillance, 6(3). https://doi.org/10.2196/20493

Rao, Q., Bai, L., LV, Y., Abdullah, A. S., Brooks, I., Xie, Y., Zhao, Y., \& Hou, X. (2020). Goal-framing and temporal-framing: Effects on the acceptance of childhood simple obesity prevention messages among preschool children's caregivers in China. International Journal of Environmental Research and Public Health, 17(3). https://doi.org/10.3390/ijerph17030770

Scheufele, D. A. (1999). Framing as a theory of media effects. Journal of Communication, 49(1), $103-$ 122. https://doi.org/10.1111/j.1460-2466.1999.tb02784.x

Shahnazi, H., Livani, M. A., Pahlavanzadeh, B., Rajabi, A., Hamrah, M. S., \& Charkazi, A. (2020). Assessing preventive health behaviors from COVID-19: A cross sectional study with health belief model in Golestan Province, Northern of Iran. Infectious diseases of poverty, 9(157). https://doi.org/10.1186/s40249-020-00776-2

SimilarWeb. (2021). Top websites ranking. Retrieved January 1, 2021, from https://www.similarweb.com/top-websites/malaysia/category/news-and-media/

Soofi, M., Najafi, F., \& Karami-Matin, B. (2020). Using insights from behavioral economics to mitigate the spread of COVID-19. Applied Health Economics Health Policy, 18, 345-350. https://doi.org/10.1007/s40258-020-00595-4

Tversky, A., \& Kahneman, D. (1981). The framing of decisions and the psychology of choice. Science, 211(4481), 453-458. https://doi.org/10.1126/science.7455683

Yuen, K. F., Li, K. X., Ma, F., \& Wang, X. (2020). The effect of emotional appeal on seafarers' safety behaviour: An extended health belief model. Journal of Transport and Health, 16. https://doi.org/10.1016/j.jth.2019.100810

Zawawi, J. W. M., Kee, C. P., \& Ahmad, F. (2014). The repetition and competition of news reporting as mediator to frame setting. [Paper presentation]. International Conference on Communication and Media, Mangkawi, Malasia. https://www.researchgate.net/publication/275544505_The_Repetition_and_Competitio n_of_News_Reporting_as_Mediator_to_Frame_Setting

Zezelj, I., Skoric, M., Bogdanovic, S., Hristic, D., \& Stokic, D. (2007). Valence framing of political preferences and resistance to persuasion. Psihologija, 40(3), 365-383. https://doi.org/10.2298/PSI0703365Z 